\title{
Prevalence, severity, and request for treatment of dental fluorosis among adults in an endemic region of Northern Nigeria
}

\author{
Paul Ikhodaro Idon ${ }^{1}$, Joan Emien Enabulele ${ }^{2}$
}

Correspondence: Dr. Paul Ikhodaro Idon

Email: idonp85@gmail.com

\begin{abstract}
'Department of Dental Surgery, University of Maiduguri Teaching Hospital, Maiduguri, Borno State, Nigeria, 2Department of Restorative Dentistry, School of Dentistry, University of Benin, Benin City, Edo State, Nigeria
\end{abstract}

\section{ABSTRACT}

Objectives: The objective was to assess the prevalence of all forms of dental fluorosis (DF), the severity, and the request for treatment as a measure of the burden of the condition among adult patients seen at a tertiary health facility in an endemic region of Northeastern Nigeria. Materials and Methods: This was a cross-sectional study that collected required information using a questionnaire from adult dental patients followed by dental examination to assess for DF. Statistical Analysis Used: Associations between sociodemographic distributions (age and gender) and prevalence were analyzed on the Statistical Package for the Social Sciences using the Chi-square test. Analysis was done at $95 \%$ confidence interval and the level of statistical significance was set at $P<0.05$. Results: Three hundred and twelve patients $(41.7 \%)$ were diagnosed with DF among the patients who resided in the endemic region with a calculated Community Fluorosis Index of 0.62 . The mean age of the affected patients was $33.8 \pm 9.2$ years, with a majority of the patients in the 16-25 (47.4\%) years' age group and a preponderance among females $(P=0.003)$. A greater proportion of the 312 diagnosed patients, 201 (64.3\%), had fluorosis of esthetic concern, while only $9.3 \%$ sought treatment. Most of these patients that sought treatment had the severe form of the enamel defect. Conclusions: DF should be considered as a condition of public health importance in this region. It is necessary to conduct a community-based study and fluoride mapping of the northeastern region as well to determine other factors that may contribute to its occurrence in this population.

Key words: Dental fluorosis, esthetics, Northeastern Nigeria, prevalence

\section{INTRODUCTION}

Adequate intake of fluoride plays an important role in the development of tooth enamel and has so far been the most effective measure against dental caries, but is also associated with the increasing prevalence of dental fluorosis (DF) as chronic excessive consumption interferes with the matrix formation and calcification of tooth enamel. ${ }^{[1-3]}$ The chronic toxic effect of excessive intake of fluoride has also been documented to include skeletal fluorosis, neurological

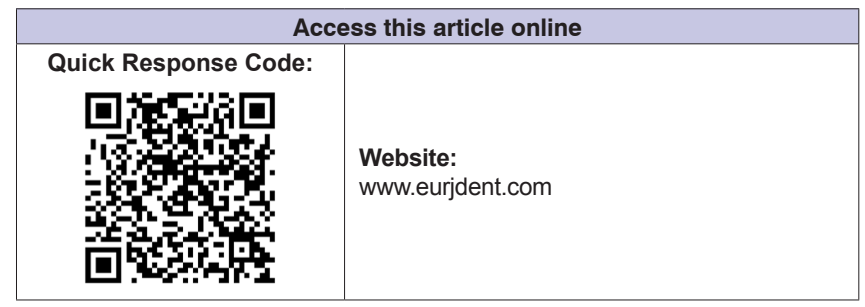

manifestations such as lowering of the intelligence quotient (IQ), gastrointestinal tract (GIT) dyspeptic symptoms, and urinary tract malfunctioning. ${ }^{[4-6]}$ These symptoms, unlike DF, have been noted mostly at higher concentrations of fluoride ranging from $2 \mathrm{mg} / \mathrm{L}$ for low IQ in children, $3.2 \mathrm{mg} / \mathrm{L}$ for GIT symptoms, $8 \mathrm{mg} / \mathrm{L}$ for renal symptoms, and $10 \mathrm{mg} / \mathrm{L}$ for crippling skeletal fluorosis. ${ }^{[4-6]}$ Among all these,

This is an open access journal, and articles are distributed under the terms of the Creative Commons Attribution-NonCommercial-ShareAlike 4.0 License, which allows others to remix, tweak, and build upon the work non-commercially, as long as appropriate credit is given and the new creations are licensed under the identical terms.

For reprints contact: reprints@medknow.com

\footnotetext{
How to cite this article: Idon PI, Enabulele JE. Prevalence, severity, and request for treatment of dental fluorosis among adults in an endemic region of Northern Nigeria. Eur J Dent 2018;12:184-90.

DOI: 10.4103/ejd.ejd_260_17
} 
DF is the most common unwanted effect of chronic exposure to fluoride, and the importance of this condition is its role as the earliest indicator of excessive fluoride exposure in a population. ${ }^{[7]}$ Unlike the other chronic toxic effects, DF becomes evident in the population at consumption concentrations above $1.5 \mathrm{mg} / \mathrm{L}$. The therapeutic range of fluoride appears to be narrow $(1-1.2 \mathrm{mg} / \mathrm{L})$, that is, between the concentration needed to protect against dental caries and at the same time avoiding the occurrence of DF. ${ }^{[8]}$ A balance therefore needs to be struck between the concentration necessary for caries prevention which will result in objectionable DF.

Water remains the major source of fluoride intake, with lesser amounts consumed in other sources such as fluoridated food supplements, toothpastes, and other dental products. ${ }^{[9-12]}$ Concentrations of fluoride in water sources for drinking of up to $1 \mathrm{mg} / \mathrm{L}$ for temperate regions and $1.2 \mathrm{mg} / \mathrm{L}$ for the tropics have been recommended to provide a balance between its anticaries effect and its potential to cause enamel defect. ${ }^{[8]}$ Concentrations below $0.5 \mathrm{mg} / \mathrm{L}$ will not protect against dental caries, while DF may be seen at a concentration of $1 \mathrm{mg} / \mathrm{L}$, but can be acceptable since it is of low prevalence and severity, as well as of little public concern in relation to the caries that would have resulted with a lower fluoride concentration. ${ }^{[13,14]}$ It is however agreed that concentrations above a threshold limit of $1.5 \mathrm{mg} / \mathrm{L}$ will result in objectionable fluorosis. ${ }^{[15]}$

Severity of the resulting DF is determined by several factors including duration of consumption, diet, duration of breastfeeding, use of fluoride supplements, age, weight, nutritional status, and altitude. ${ }^{[16-19]}$ Increased risk of DF has been noted with decreased duration of breastfeeding and subsequent introduction of infant formulas; ${ }^{[12,20]}$ use of fluoridated toothpaste at an early age ( $<2$ years of age) ${ }^{[20]}$ younger aged children, as fluoride uptake by mineralized tissues decreases with increasing age ${ }^{[21]}$ and the use of fluoride supplements. ${ }^{[22]}$ Similar doses of fluoride may therefore produce different levels of severity of DF depending on these factors. Studies have been carried out to explain the relationship between these factors and the prevalence and severity of DF. The criticism of a majority of them however has been the cross-sectional design nature of these studies, which is not ideal for studying these factors. ${ }^{[19]}$ Mild-to-moderate forms of DF present with fine opaque lines distributed to different degrees over the enamel surface, while the severe forms become completely opaque and porous acquiring stains, giving a brownish/black appearance. The appearance of this discoloration as well as pitting of the enamel surface may become esthetically objectionable enough to trigger social constraints for the sufferers. ${ }^{[23,24]}$ Furthermore, the resulting dentine exposure from enamel pitting has been documented as an etiological factor for dentine hypersensitivity. ${ }^{[25]}$

Assessment of the prevalence and severity of DF has been carried out using several diagnostic scoring indices. They include the Thylstrup-Fejerskov Index $(\mathrm{TFI}){ }^{[26]}$ the Tooth Surface Index of Fluorosis, ${ }^{[27]}$ the Fluorosis Risk Index, ${ }^{[28]}$ and the Dean's Fluorosis Index (DFI). ${ }^{[29]}$ The two most commonly used are the TFI and the DFI. The DFI scores only the anterior teeth unlike the TFI, which scores all fluorotic teeth and also reflects the histopathologic features that correlate with the clinical features seen in these teeth. ${ }^{[26,29]}$ The DFI and its modifications however remain the gold standard index for DF and has been in use the longest as well as the most widely used in epidemiological studies. ${ }^{[30]}$

Although it is a late measure of fluoride exposure in a population, DF remains the most sensitive sign of prolonged high fluoride exposure. ${ }^{[31]}$ This is exemplified by the prevalence rates and severity in populations that are endemic for DF due to excessive amounts of fluoride in groundwater and surface water. Prevalence rates of $11.3 \%-100 \%$ have been reported across populations, with the higher rates and severity noted in endemic regions where the fluoride concentration far exceeds the recommended guideline value. ${ }^{[32-34]}$ High prevalence rates in places such as India, China, East African Rift valley region, and Northern Nigeria have been linked to the high fluoride concentration in groundwater sources of drinking water. ${ }^{[32,33]}$ In Nigeria, the occurrence of DF in schoolchildren and adults from four northeastern areas of Adamawa, Yobe, Bauchi, and Bornu States had been reported by Wilson ${ }^{[35]}$ as far back as 1954 . More recent studies have provided prevalence rates ranging from $11.3 \%$ in the southern part to $51 \%$ in the northern region. ${ }^{[34,36,37]}$ The higher rates in the northern part of the country have been related to the concentration of fluoride in groundwater sources of drinking water, such as wells and boreholes. High concentrations of fluoride in surface and groundwater in the north central and northeastern regions have been noted by several researchers with values as high as $5.6 \mathrm{mg} / \mathrm{L}$ in Maiduguri, ${ }^{[38-40]}$ a region in which groundwater such as wells and boreholes remain the main source of drinking water. ${ }^{[4]]}$ 
Ascertaining the public health importance of DF with the intent of prevention and treatment should include having definite prevalence figures, both for all levels of fluorosis and for fluorosis of esthetic concern; concentration of fluoride in the sources of drinking water; the perception of the effect of DF on those affected; and the need for treatment as measured by the request for treatment by sufferers. Extensive research has been carried out to assess the fluoride content of water in this region. Although DF has been reported, there appears to be no documented prevalence or treatment need in this region known to be endemic for the condition. The aim of this study was therefore to assess the prevalence, severity of $\mathrm{DF}$, and the request for treatment as a measure of the burden of the condition among adult patients seen at a tertiary health facility in Maiduguri, Borno State.

\section{MATERIALS AND METHODS}

\section{Study design and participants}

This was a cross-sectional descriptive study involving all adult patients who presented at the oral diagnosis clinic of the University of Maiduguri Teaching Hospital, Maiduguri, over a period of 12 months. Ethical approval for the study was granted by the Research and Ethics Committee of the hospital. Informed consent was sought and obtained from each patient and participation was voluntary. Data were collected by means of a predesigned questionnaire, which collected demographic information as well as patient's primary reason for attendance, previous treatment for DF, place of residence during the first 8 years of life, and sources of drinking water during that period. Dental examinations for presence and assessment of severity of DF were conducted by two trained and calibrated examiners using the DFI. Precalibration of the two examiners was carried out prior to the study during a pretest where the examiners conducted duplicate examinations on patients with DF using the DFI. A strong measure of agreement (Cohen's Kappa) was observed between the two examiners $(\kappa=0.92)$.

For assessment of DF, the teeth were dried with gauze and then the facial/buccal surface of all the upper permanent teeth was evaluated by visual inspection in natural light, using a dental mirror and explorer. The registry of DF was based on the two most affected teeth using the DFI to classify the severity for each patient as "normal," "questionable," "very mild," "mild," "moderate" or "severe," coded as $0,1,2,3,4$, and 5 , respectively.

\section{Data analysis}

Data analysis was done with Statistical Package for Social Sciences (SPSS) for Windows (version 20, SPSS Inc., Chicago, IL, USA). The prevalence of DF was determined by the following formula:

$$
P=\frac{\begin{array}{l}
\text { Proportion of the population with very } \\
\text { mild or higher levels of dental fluorosis }
\end{array}}{\text { Total population }} \times 100
$$

Where $P=$ Prevalence

To determine the Community Fluorosis Index (CFI) as proposed by Dean and Elvove, ${ }^{[42]}$ each grade/classification of DFI severity was given a statistical weight, $p$, with values $0,0.5,1,2,3$, and 4 for "normal," "questionable," "very mild," "mild," "moderate," or "severe," respectively. The CFI was then estimated as follows:

$$
C F I=\frac{\sum\left(\begin{array}{c}
\text { Number of patients with flourosis } \times \\
\text { statistical weight }
\end{array}\right)}{\text { Total number of patients examined }}
$$

\begin{tabular}{ll}
\multicolumn{2}{l}{ And the scores are as interpreted below: } \\
\hline CFI value range & Public health significance \\
\hline $0.0-0.4$ & Negative \\
$0.4-0.6$ & Borderline \\
$0.6-1.0$ & Slight \\
$1.0-2.0$ & Medium \\
$2.0-3.0$ & Marked \\
$3.0-4.0$ & Very marked \\
\hline
\end{tabular}

CFI: Community fluorosis index

Dean and Evolve ${ }^{[42]}$ stated that a CFI that is above 0.6 indicates that the condition is a public health problem and it justifies an increased attention to the population. Chi-square test was used to determine the association between sociodemographic distribution (age and gender) and prevalence of DF at 95\% confidence interval. Where necessary, the level of statistical significance was set at $P<0.05$.

\section{RESULTS}

A total of 1032 adult patients with a mean age of $31.8 \pm 10.4$ years were seen during the study period. Three hundred and twelve of these patients were diagnosed with DF. This gave an overall hospital prevalence rate of $30.2 \%$. Prevalence was highest among the $16-25$ years' age group and decreased with increasing age among the patients $(P=0.000)$. Prevalence was also higher among the female patients examined [Table 1].

European Journal of Dentistry, Volume 12 / Issue 2 / April-June 2018 
Seven hundred and forty-eight (72.5\%) patients had resided in the northeastern states during early childhood. None of the patients who resided outside the region was diagnosed with DF, thus the actual prevalence, that is, the prevalence of DF among patients who resided in the region was $41.7 \%$ [Table 2].

The ages of the patients diagnosed with DF ranged from 20 to 53 years with a mean age of $33.8 \pm 9.2$ years. The majority of the patients were in the 16-25 (47.4\%) years' age group, while the gender distribution showed a preponderance among females $(P=0.003)$ [Table 3]. Prevalence of DF was affected by the source of drinking water among the patients from the northeastern

\begin{tabular}{lccc}
\multicolumn{2}{l}{$\begin{array}{l}\text { Table 1: Prevalence of dental fluorosis by age group } \\
\text { and gender }\end{array}$} \\
\hline \multicolumn{4}{c}{ DF } \\
\cline { 2 - 4 } & Present, $\boldsymbol{n}(\%)$ & Absent, $\boldsymbol{n}(\%)$ & Total, $\boldsymbol{n}(\%)$ \\
\hline Age group (years) & $148(14.3)$ & $164(15.9)$ & $312(30.2)$ \\
$16-25$ & $126(12.2)$ & $251(24.3)$ & $377(36.5)$ \\
$26-35$ & $25(2.4)$ & $193(18.7)$ & $218(21.1)$ \\
$36-45$ & $13(1.3)$ & $77(7.5)$ & $90(8.7)$ \\
$46-55$ & 0 & $29(2.8)$ & $29(2.8)$ \\
$56-65$ & 0 & $6(0.6)$ & $6(0.6)$ \\
$66-75$ & & & \\
Gender & $123(11.9)$ & $361(35.0)$ & $484(46.9)$ \\
Male & $189(18.3)$ & $359(34.8)$ & $548(53.1)$ \\
Female & $312(30.2)$ & $720(69.8)$ & $1032(100.0)$ \\
Total &
\end{tabular}

Likelihood ratio (age: $\chi^{2}=123.140, \mathrm{df}=5, P=0.000$ ), Pearson's Chi-square test (gender: $\left.\chi^{2}=10.037, \mathrm{df}=1, P=0.002\right)$. DF: Dental fluorosis

\begin{tabular}{|c|c|c|c|}
\hline \multirow[t]{2}{*}{ Residence } & \multicolumn{3}{|c|}{ DF } \\
\hline & Present, $\boldsymbol{n}(\%)$ & Absent, $n(\%)$ & Total, $\boldsymbol{n}(\%)$ \\
\hline Borno & $236(31.6)$ & $168(22.5)$ & $404(54.0)$ \\
\hline Yobe & $46(6.1)$ & $85(11.4)$ & $131(17.5)$ \\
\hline Adamawa & $15(2.0)$ & $80(10.7)$ & $95(12.7)$ \\
\hline Gombe & $10(1.3)$ & $50(6.7)$ & $60(8.0)$ \\
\hline Bauchi & $5(0.7)$ & $41(5.5)$ & $46(6.1)$ \\
\hline Taraba & $0(0)$ & $12(1.6)$ & $12(1.6)$ \\
\hline Total & $312(41.7)$ & $436(58.3)$ & $748(100.0)$ \\
\hline
\end{tabular}

\begin{tabular}{lccc}
\multicolumn{4}{l}{ Table 3: Gender distribution of patients with DF by age groups } \\
\hline Age group (years) & Male, $\boldsymbol{n}(\%)$ & Female, $\boldsymbol{n}(\%)$ & Total, $\boldsymbol{n}(\%)$ \\
\hline $16-25$ & $46(14.7)$ & $102(32.7)$ & $148(47.4)$ \\
$26-35$ & $55(17.6)$ & $71(22.8)$ & $126(40.4)$ \\
$36-45$ & $12(3.8)$ & $13(4.2)$ & $25(8.0)$ \\
$46-55$ & $10(3.2)$ & $3(1.0)$ & $13(4.2)$ \\
Total & $123(39.3)$ & $189(60.7)$ & $312(100)$
\end{tabular}

Fisher's Chi-square test $\left(\chi^{2}=13.681, \mathrm{df}=3, P=0.00\right)$. $\mathrm{DF}$ : Dental fluorosis region [Table 4]. A higher proportion of those who sourced water from wells were diagnosed with DF than those who used other sources.

Among the 312 patients diagnosed with DF, 201 (64.3\%) had fluorosis of esthetic concern (mild, moderate, or severe) [Figure 1], but only $9.3 \%$ attended clinic primarily to seek treatment for the condition. Statistics showed this to be statistically significant only for the degree of severity among the patients. The majority of the patients with DF seeking treatment had the severe form of enamel defect [Table 5]. The CFI for the patients was calculated to be 0.62 [Table 6] which is in the "slight" category of public health importance.

\section{DISCUSSION}

DF can serve as an indicator of excessive fluoride exposure in a population. In a review of oral health in Nigeria, DF was identified as one of the oral health concerns that is endemic in the northern part of the country. ${ }^{[43]}$ The prevalence of the condition in any population is one way of determining its public health significance. This study presents two prevalence figures: one $(30.2 \%)$ among the total number of patients seen in an outpatient dental clinic of a teaching hospital and second $(41.7 \%)$ among a subgroup of the patients who resided in the region in their early years and were exposed to water sources containing excessive amounts of fluoride in an area endemic for DF. Both of these figures are in the higher range of prevalence figures reported in Nigeria $(11.3 \%-51 \%)$ and closer to that reported in other endemic areas of Northern Nigeria. ${ }^{[34,36,37]}$ Okoye $^{[34]}$ reported $11.3 \%$ in the southeast, $11.4 \%$ by Ajayi et al. ${ }^{[44]}$ in the southwest, while Akosu et al., ${ }^{[17]}$ Wongdem et al., ${ }^{[37]}$ and El-Nadeef and Honkala ${ }^{[36]}$ reported prevalences of $22.2 \%, 26.1 \%$ and $51 \%$ in the

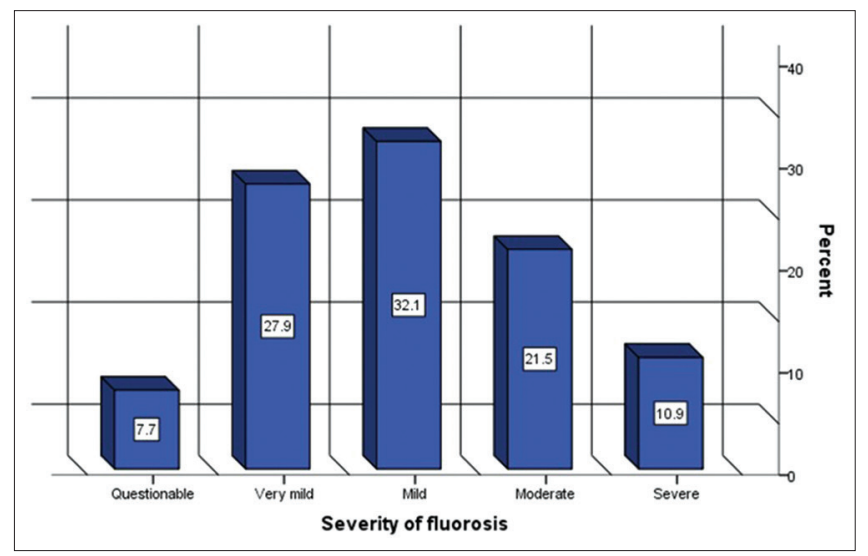

Figure 1: Distribution of severity of dental fluorosis among the affected patients 


\begin{tabular}{|c|c|c|c|}
\hline \multirow[t]{2}{*}{ Source of water } & \multicolumn{3}{|c|}{ DF } \\
\hline & $\begin{array}{c}\text { Present, } \\
n(\%)\end{array}$ & $\begin{array}{c}\text { Absent, } \\
n(\%)\end{array}$ & $\begin{array}{l}\text { Total, } \\
n(\%)\end{array}$ \\
\hline Wells & $33(4.4)$ & $26(3.5)$ & $59(7.9)$ \\
\hline Boreholes & $97(13.0)$ & $123(16.4)$ & $220(29.4)$ \\
\hline Public water supply & $69(9.2)$ & $98(13.1)$ & $167(22.3)$ \\
\hline Rivers & $0(0.0)$ & $3(0.4)$ & $3(0.4)$ \\
\hline Wells + boreholes & $16(2.1)$ & $29(3.9)$ & $45(6.0)$ \\
\hline Wells + public water & $15(2.0)$ & $39(5.2)$ & $54(7.2)$ \\
\hline $\begin{array}{l}\text { Boreholes + public } \\
\text { water supply }\end{array}$ & $82(11.0)$ & $118(15.8)$ & $200(26.7)$ \\
\hline Total & $312(41.7)$ & $436(58.3)$ & $748(100.0)$ \\
\hline
\end{tabular}

Likelihood ratio $\left(\chi^{2}=13.855, \mathrm{df}=6, P=0.031\right)$. DF: Dental fluorosis

\begin{tabular}{|c|c|c|c|}
\hline & DF, $n(\%)$ & Others, $n(\%)$ & Total, $\boldsymbol{n}(\%)$ \\
\hline \multicolumn{4}{|c|}{ Age group (years) } \\
\hline $16-25$ & $16(5.1)$ & $132(42.3)$ & $148(47.4)$ \\
\hline $26-35$ & $12(3.8)$ & $114(36.5)$ & $126(40.4)$ \\
\hline $36-45$ & $1(0.3)$ & $24(7.7)$ & $25(8.0)$ \\
\hline $46-55$ & $0(0.0)$ & $13(4.2)$ & $13(4.2)$ \\
\hline \multicolumn{4}{|l|}{ Gender } \\
\hline Male & $7(2.2)$ & $116(37.2)$ & $123(39.4)$ \\
\hline Female & $22(7.1)$ & $167(53.5)$ & $189(60.6)$ \\
\hline \multicolumn{4}{|l|}{ Severity } \\
\hline Questionable & $0(0.0)$ & $24(7.7)$ & $24(7.7)$ \\
\hline Very mild & $0(0.0)$ & 87 (27.9) & $87(27.9)$ \\
\hline Mild & $4(1.3)$ & $96(30.8)$ & $100(32.0)$ \\
\hline Moderate & $11(3.5)$ & $56(17.9)$ & $67(21.5)$ \\
\hline Severe & $14(4.5)$ & $20(6.4)$ & $34(10.9)$ \\
\hline Total & $29(9.3)$ & $283(90.7)$ & $312(100.0)$ \\
\hline
\end{tabular}

\begin{tabular}{lcccc}
\multicolumn{5}{l}{ Table 6: Community Fluorosis Index } \\
\hline $\begin{array}{l}\text { Dean's } \\
\text { severity } \\
\text { levels of } \\
\text { DF }\end{array}$ & $\begin{array}{c}\text { Dean's } \\
\text { statistical } \\
\text { weight } \\
\text { for DF (a) }\end{array}$ & $\begin{array}{c}\text { Frequency } \\
\text { of patients } \\
\text { per severity } \\
\text { level (b) }\end{array}$ & $\begin{array}{c}\text { Product } \\
\text { (a.b) }\end{array}$ & $\begin{array}{c}\text { CFI index } \\
\text { (a.b/c) }\end{array}$ \\
\hline Normal & 0 & 720 & 0 & \\
Questionable & 0.5 & 24 & 12 & \\
Very mild & 1 & 87 & 87 & 0.62 \\
Mild & 2 & 100 & 200 & \\
Moderate & 3 & 67 & 201 & \\
Severe & 4 & 34 & 136 & \\
Total & \multicolumn{5}{c}{ C=1032 } \\
\hline CFl: Community Fluorosis Index, DF: Dental fluorosis
\end{tabular}

northcentral region. The higher values reported in the northcentral region in Plateau State have been related to the high levels of fluoride concentration found in the sources of drinking water in the region. ${ }^{[37]}$ Likewise, recent studies in the northeastern region have reported fluoride concentrations that ranged from 0.02 to $5.0 \mathrm{mg} / \mathrm{L}$, with several samples above $1.5 \mathrm{mg} / \mathrm{L}$ spanning across five of the six northeastern states. ${ }^{[40,45,46]}$ Although the prevalence values from this study may be compared to that from other endemic regions of the globe, occurrence of DF can vary widely among different locations having almost the same fluoride concentrations in the drinking water. This is so as exposure to other sources of fluoride intake, as well as other factors that determine the occurrence and severity of DF, differs among populations.

The other way of determining the public health importance of DF is by calculating the CFI for the population. The CFI in this study is a little over 0.6, indicating a fluorosis level that is of public health concern. The CFI can be considered to be a better measure of public health significance compared to prevalence alone as it measures both prevalence and severity in the study population. Due to the higher statistical weights assigned to the higher levels of severity of DF, the CFI values would be higher in populations with more individuals in the higher levels of DF severity. Although a high prevalence of $41.7 \%$ was observed in this population, the CFI was just slightly above borderline since the majority of those affected had very mild or mild forms of DF. Prevalences have been found to vary between the genders, while some other studies have found no association of DF to gender. ${ }^{[33,47-49]}$ With the higher female clinic attendance in this study, it is not surprising to find a higher prevalence of DF among females. This may also be explained by the closer attention that females tend to pay to their health and appearance, as shown by a higher proportion of the females attending clinic primarily for treatment of DF. In like manner, the findings of this study wherein the prevalence of DF was observed to decrease with increasing age may be a fall out of the desire for improved esthetics among the younger age group.

It is established that DF results from prolonged exposure to excessive fluoride during tooth mineralization. Therefore, if there is no exposure to excess fluoride during childhood, it is unlikely for DF to occur. The findings of this study tend to support this assertion as none of the patients who resided outside the region was diagnosed of DF. This however does not explain the reason for the absence of DF among the other patients who resided in the region. A higher proportion of those who had water from the same 
type of water sources were not diagnosed with DF in this study. This can be explained by the difference in concentration of fluoride in water sources at specific locations as well as other factors that are considered to be essential in the pathogenesis of DF. ${ }^{[16,18]}$

Patients who used wells as their sole source of drinking water had the highest proportion of DF, while those who consumed water from rivers had the least. This is similar to observations from a similar study by Sudhir et al. ${ }^{[47]}$ The result from the present study should however be interpreted with caution since only three patients used rivers as their source of drinking water. Fluoride is present in both surface waters (rivers, springs) and groundwater (wells, boreholes). The concentration could however be higher in groundwater than in surface water due to physical, geological, and chemical contents of the aquifer, the temperature, the action of other chemical elements, and the depth of wells or boreholes. ${ }^{[50]}$

There is controversy in the literature about the level at which DF becomes esthetically objectionable. In this study, DF of esthetic concern was recorded as Dean's fluorosis severity levels of "mild" and above and accounted for the majority $(64.3 \%)$ of those affected. The request for treatment among the affected patients was however low. The reason for this is unknown, but may be due to social norms and beliefs in the region that could have an impact on the perception of esthetics. On the other hand, other researchers have stated that severity levels of "mild" and below may not be associated with esthetic concerns. This may be the reason why the moderate and severe forms accounted for majority of the few patients who attended the dental clinic primarily to seek treatment for the condition. Hence, though the proportion of the sufferers seeking treatment in the present study is quite low, there seems to be more esthetic concern with increasing degree of severity of the DF which is similar to reports of other studies. ${ }^{[51,52]}$ Like the prevalence values in this study, the distribution of severity levels may be compared to other studies, ${ }^{[48,53]}$ but its significance may be limited if fluoride mapping of sources of drinking water and other sources of fluoride is not compared at the same time among these populations.

\section{CONCLUSIONS}

This study shows that DF has a high prevalence among dental patients from the northeastern region and should be seen as a condition of public health significance. The prevalence of esthetically objectionable fluorosis is also high among these patients as is shown by their request for treatment. It would therefore be of public health benefit to conduct a community-based prevalence study as well as fluoride mapping of the northeastern region. It is important as well to determine other factors, including other sources of fluoride intake that may contribute to its occurrence in this population.

\section{Financial support and sponsorship}

Nil.

\section{Conflicts of interest}

There are no conflicts of interest.

\section{REFERENCES}

1. Adanir N, Türkkahraman H, Güngör AY. Effects of fluorosis and bleaching on shear bond strengths of orthodontic brackets. Eur J Dent 2007;1:230-5.

2. Erdal S, Buchanan SN. A quantitative look at fluorosis, fluoride exposure, and intake in children using a health risk assessment approach. Environ Health Perspect 2005;113:111-7.

3. Akpata ES. Therapeutic management of dental fluorosis: A critical review of literature. S J Oral Sci 2014;1:3-13.

4. Ozsvath DL. Fluoride and environmental health: A review. Rev Environ Sci Bio Technol 2009;8:59-79.

5. Yang K, Liang X. Fluoride in Drinking Water: Effect on Liver and Kidney Function. New York: Elsevier; 2011. p. 769-75.

6. Ranjan R, Ranjan A. Fluoride Toxicity in Animals. New York: Springer. 2015.

7. Do LG, Ha DH, Spencer AJ. Natural history and long-term impact of dental fluorosis: A prospective cohort study. Med J Aust 2016;204:25.

8. World Health Organization. Guideline for Drinking Water Quality Health Criteria and other Supporting Information. WHO. $2^{\text {nd }}$ ed., Vol. 02. Geneva, Switzerland: World Health Organization; 1997a.

9. Harrison PT. Fluoride in water: A UK perspective. J Fluorine Chem 2005;126:1448-56.

10. Marczuk-Kolada G, Luczaj-Cepowicz E, Waszkiel D, Szarmach I, Jakoniuk P, Mystkowska J. Fluoride release and antibacterial properties of the polyacid-modified composite Dyract Ap (R). Fluoride 2009;42:147-51.

11. Zafar MS. Effects of surface prereacted glass particles on fluoride release of dental restorative materials. World Appl Sci J 2013;28:457-62

12. Ullah R, Zafar MS, Shahani N. Potential fluoride toxicity from oral medicaments: A review. Iran J Basic Med Sci 2017;20:841-8.

13. Rugg-Gunn AJ, Spencer AJ, Whelton HP, Jones C, Beal JF, Castle P, et al. Critique of the review of 'water fluoridation for the prevention of dental caries' published by the Cochrane collaboration in 2015 . Br Dent J 2016;220:335-40.

14. World Health Organization. World Health Organization Guidelines. In: Handbook of Drinking Water Quality, WHO. $3^{\text {rd }}$ ed. Geneva, Switzerland: World Health Organization; 2004. p. 527-34.

15. World Health Organization. Guidelines for Drinking Water Quality. Recommendations. Vol. 1. Geneva: World Health Organization; 1984

16. Robinson C, Connell S, Kirkham J, Brookes SJ, Shore RC, Smith AM, et al. The effect of fluoride on the developing tooth. Caries Res 2004;38:268-76.

17. Akosu TJ, Zoakah AI. Risk factors associated with dental fluorosis in central plateau state, Nigeria. Community Dent Oral Epidemiol 2008;36:144-8.

18. Kumar JV, Swango PA. Fluoride exposure and dental fluorosis in Newburgh and Kingston, New York: Policy implications. Community Dent Oral Epidemiol 1999;27:171-80.

19. Mascarenhas AK. Risk factors for dental fluorosis: A review of the recent literature. Pediatr Dent 2000;22:269-77. 
20. Osuji OO, Leake JL, Chipman ML, Nikiforuk G, Locker D, Levine N, et al. Risk factors for dental fluorosis in a fluoridated community. J Dent Res 1988;67:1488-92.

21. Buzalaf MA, Whitford GM. Fluoride metabolism. Monogr Oral Sci 2011;22:20-36.

22. Riordan PJ, Banks JA. Dental fluorosis and fluoride exposure in Western Australia. J Dent Res 1991;70:1022-8.

23. Yildiz G, Celik EU. A minimally invasive technique for the management of severely fluorosed teeth: A two-year follow-up. Eur J Dent 2013;7:504-8.

24. Chankanka O, Levy SM, Warren JJ, Chalmers JM. A literature review of aesthetic perceptions of dental fluorosis and relationships with psychosocial aspects/oral health-related quality of life. Community Dent Oral Epidemiol 2010;38:97-109.

25. Tonguc MO, Ozat Y, Sert T, Sonmez Y, Kirzioglu FY. Tooth sensitivity in fluorotic teeth. Eur J Dent 2011;5:273-80.

26. Thylstrup A, Fejerskov O. Clinical appearance of dental fluorosis in permanent teeth in relation to histological changes. Community Dent Oral Epidemiol 1978;6:315-28.

27. Horowitz HS, Driscoll WS, Meyers RJ, Heifetz SB, Kingman A. A new method for assessing the prevalence of dental fluorosis-the tooth surface index of fluorosis. J Am Dent Assoc 1984;109:37-41.

28. Pendrys DG. The fluorosis risk index: A method for investigating risk factors. J Public Health Dent 1990;50:291-8.

29. Dean HT. The investigation of physiologic effects by epidemiological method. In: Moulton FR, editor. Fluoride and Dental Health. $1^{\text {st }}$ ed. Washington DC: American Association for Advancement of Science; 1942. p. 23-31.

30. Rozier RG. Epidemiologic indices for measuring the clinical manifestations of dental fluorosis: Overview and critique. Adv Dent Res 1994;8:39-55.

31. Riordan PJ. Perceptions of dental fluorosis. J Dent Res 1993;72:1268-74.

32. Rango T, Kravchenko J, Atlaw B, McCornick PG, Jeuland M, Merola B, et al. Groundwater quality and its health impact: An assessment of dental fluorosis in rural inhabitants of the main Ethiopian rift. Environ Int 2012;43:37-47.

33. Vellathurai C, Sri Renganathan P, Selvaraj V. Severity of dental fluorosis in association with socioeconomic status among middle school children in Sivagiri taluk, Tirunelveli district, Tamilnadu, India. Int J Appl Res 2016;2:426-9.

34. Okoye LO. Prevalence of Dental Fluorosis among school children in South-Eastern, Nigeria. Miami Florida: Presented in the International Association for Dental Research 87 $7^{\text {th }}$ General Session; 2009.

35. Wilson DC. Fluorine content of some Nigerian waters. Nature 1954;173:305.

36. El-Nadeef MA, Honkala E. Fluorosis in relation to fluoride levels in water in central Nigeria. Community Dent Oral Epidemiol 1998;26:26-30.

37. Wongdem JG, Aderinokun GA, Sridhar MK, Selkur S. Prevalence and distribution pattern of enamel fluorosis in Langtang town, Nigeria. Afr J Med Med Sci 2000;29:243-6.
38. Edmunds WM, Fellman E, Goni IB. Lakes, groundwater and palaeohydrology in the Sahel of NE Nigeria: Evidence from hydrogeochemistry. J Geol Soc 1999;156:345-55.

39. Lar UA, Dibal HU, Daspan R, Jaryum SW. Fluoride occurrence in the surface and groundwater of Fobur area of Jos East LGA of Plateau States. J Environ Sci II 2007;2:99-105.

40. Bura B, Goni IB. Tracing the factors influencing occurrence of fluoride in groundwater of the Middle zone aquifer in Borno State, North-Eastern Nigeria. J Min Geol 2012;48:177-84.

41. Lar UA, Dibal HU, Schoeneich K. Fluoride in groundwater in Nigeria: Origin and human health impact. Am J Environ Prot 2014;3:66-9.

42. Dean HT, Elvove E. Studies on the minimal threshold of the dental sign of chronic endemic dental fluorosis (mottled enamel). Pub Health Report 1935;50:1719-29.

43. Akpata ES. Oral health in Nigeria. Int Dent J 2004;54:361-6.

44. Ajayi DM, Arigbede AO, Dosumu OO, Ufomata D. The prevalence and severity of dental fluorosis among secondary school children in Ibadan, Nigeria. Niger Postgrad Med J 2012;19:102-6.

45. Dibal HU, Schoeneich K, Garba I, Lar UA, Bala EA. Overview of fluoride distribution in major aquifer units of northern Nigeria. Health 2012;4:1287-94.

46. Dibal HU, Lar UA. Preliminary survey of fluoride concentrations in the groundwater of Kaltungo Town and Environs. Gombe State. Northeastern Nigeria: Water quality and health implications. J Environ Sci 2005; 17:736-42

47. Sudhir KM, Prashant GM, Subba Reddy VV, Mohandas U, Chandu GN. Prevalence and severity of dental fluorosis among 13 to 15-year-old school children of an area known for endemic fluorosis: Nalgonda district of Andhra Pradesh. J Indian Soc Pedod Prev Dent 2009;27:190-6.

48. Dubey HV, Ingle NA, Gupta R, Charania Z, Ingle E, Sharma I. Prevalence of dental fluorosis among 12-15 years school children of Bharatpur city: A cross-sectional study. J Indian Assoc Public Health Dent 2015;13:405-9.

49. Rigo L, Caldas AF, de Souza EH. Factors associated with dental fluorosis. Rev Odonto Ciênc 2010;25:8-14.

50. Paul ED, Gimba CE, Kagbu JA, Ndukwe GI, Okibe FG. Spectrometric determination of fluoride in water, soil and vegetables from the precinct of River Basawa, Zaria. Nigeria J Basic Appl Chem 2011;1:33-8.

51. McGrady MG, Ellwood RP, Goodwin M, Boothman N, Pretty IA. Adolescents' perceptions of the aesthetic impact of dental fluorosis vs. Other dental conditions in areas with and without water fluoridation. BMC Oral Health 2012;12:4.

52. Browne D, Whelton H, O'Mullane D, Tavener J, Flannery E. The aesthetic impact of enamel fluorosis on Irish adolescents. Community Dent Oral Epidemiol 2011;39:127-36.

53. Medina-Solis CE, Pontigo-Loyola AP, Maupome G, Lamadrid-Figueroa H, Loyola-Rodríguez JP, Hernández-Romano J, et al. Dental fluorosis prevalence and severity using dean's index based on six teeth and on 28 teeth. Clin Oral Investig 2008;12:197-202. 